\title{
Multi-Phase Buck Converters with Extended Duty Cycle
}

\author{
Yungtaek Jang, Milan M. Jovanović, and Yuri Panov \\ Power Electronics Laboratory \\ Delta Products Corporation \\ P.O. Box 12173, 5101 Davis Drive \\ Research Triangle Park, NC 27709
}

\begin{abstract}
A family of multi-phase, pulse-width-modulated (PWM) step-down converters that exhibit high input-to-output voltage conversion ratios is introduced. The proposed converters operate with larger duty cycles and lower voltage stresses on the switches than their conventional converter counterparts making them suitable for applications in high-frequency, non-isolated point-of-load converters employed in powering today's microprocessors.
\end{abstract}

\section{INTRODUCTION}

Today, multi-phase, interleaved, synchronous-rectifier buck converters are extensively used as point-of-load regulators for modern high-performance microprocessors that require very low output voltages and fast dynamic responses [1], [2]. These modular or embedded point-of-load converters, which are known as voltage regulators (VRs), have the output voltage in the $0.8-1.3-\mathrm{V}$ range and need to provide very high currents, very often in excess of $100 \mathrm{~A}$, to highly dynamic microprocessor loads that exhibit current slew rates as high as 400-500 A/ $\mu$ s. In the majority of applications VRs are powered from the $12-\mathrm{V}$ output of an acdc power supply (i.e., silver box).

Due to a very low output voltage, the duty cycle of the $12-\mathrm{V}$ input VRs is very narrow, i.e., it is only around $10 \%$. Moreover, with anticipated future reductions of the microprocessor supply voltage, the duty cycle will be reduced even further. Generally, a small duty cycle has a detrimental effect on the VR efficiency and load transient response [2], [3]. In addition, a very small duty cycle limits the maximum attainable switching frequency because the conduction time of the high-side switch cannot be controlled when it becomes shorter than the driver rise/fall time.

One method to overcome the performance limitations of a short duty cycle is to employ a two-stage approach [4]. In this approach, the $12-\mathrm{V}$ input voltage is stepped down to an optimal level by a pre-regulator stage before it is applied to a multi-phase interleaved buck converter output stage. While it has been demonstrated that this approach can improve the overall performance of the $12-\mathrm{V} \mathrm{VR}$, it has not gained acceptance in industry due to an increased number of components and, more importantly, an increased cost.
Another approach to deal with a small duty cycle of the $12-\mathrm{V} \mathrm{VRs}$ is to develop single-stage multi-phase buckderived topologies with extended duty cycles. So far, a number of these topologies have been discussed in the literature. The proposed topologies employ either transformers or coupled inductors to achieve a duty-cycle extension, i.e., to increase the step-down voltage conversion ratio of the buck converter. The transformer-based topologies, for example, include the phase-shifted full-bridge converter [3], the push-pull forward converter [5], the pushpull converter [6], and the half-bridge converter [7]. The coupled-inductor implementations reported in [8]-[10] are based on the tapped-inductor buck converter. Generally, the performance of all these implementations is adversely affected by leakage inductances of their magnetic components, limiting their switching-frequency range and performance.

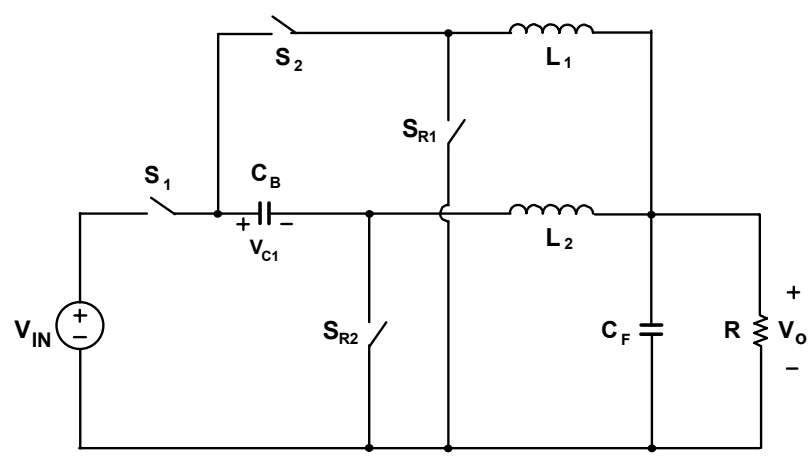

(a)

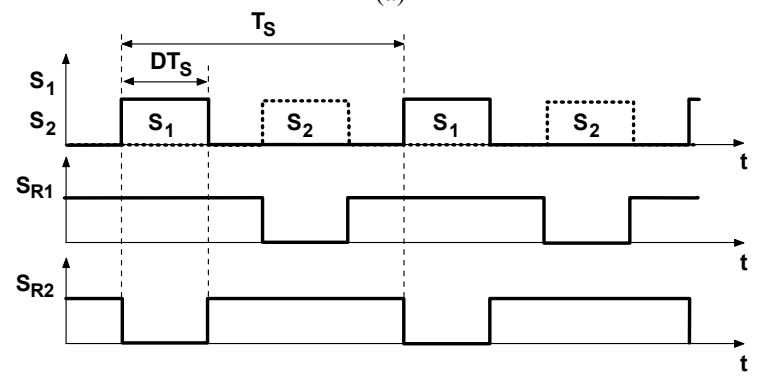

(b)

Fig. 1. Two-inductor, two-switch PWM buck converter: (a) circuit diagram; (b) switch timing diagrams. 


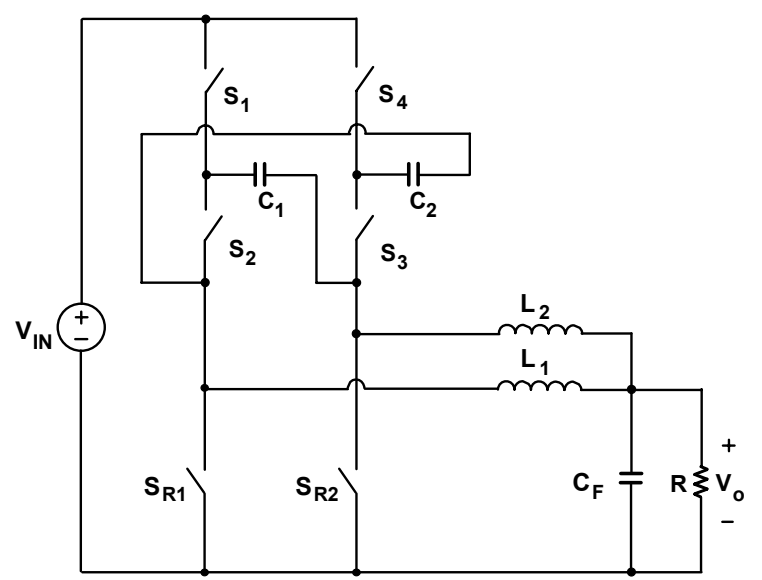

(a)

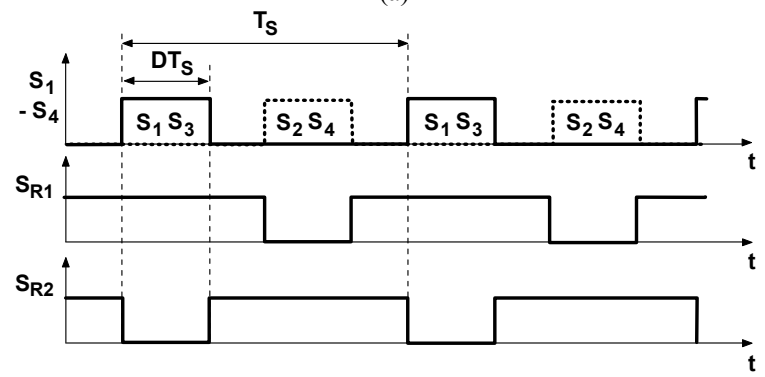

(b)

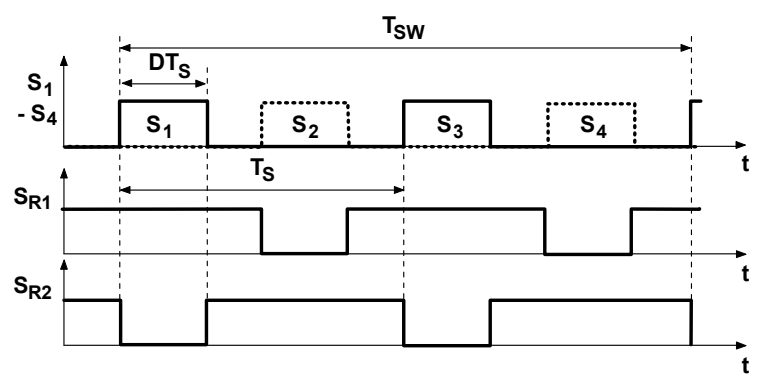

(c)

Fig. 2. Two-inductor, four-switch PWM buck converter: (a) circuit diagram; (b) switch timing diagrams for two-phase interleaved control; (c) switch timing diagrams for four-phase interleaved control.

In this paper, a family of multi-phase PWM converters that provide extended duty cycle without the use of magnetic components is introduced. The proposed multi-phase stepdown converters operate with larger duty cycles and lower voltage stresses on the switches than their conventional buck converter counterparts. Since these converters do not use magnetic components to extend the duty cycle, they have the potential of operating at a high switching frequency without a degradation of performance.

\section{Multi-Phase PWM Buck CONVERTERS With EXTENDED DUTY CYCLE}

Figures 1(a) and 1(b) show the circuit diagram and switch timing waveforms, respectively, of the two-inductor, two- switch buck converter with extended duty cycle. The circuit in Fig. 1(a) exhibits the same voltage-conversion ratio (voltage gain) as the conventional single, or multi-phase buck converter, but with a duty cycle that is twice as large as that of the conventional buck converter.

The implementation of the two-inductor, four-switch PWM buck converter is shown in Fig. 2(a). Generally, this converter can be controlled either by two-phase or four-phase interleaved control. The timing diagrams of the switches for the two-phase interleaved control are shown in Fig. 2(b), whereas the timing diagrams for the four-phase interleaved control with counter clockwise sequence $\mathrm{S}_{1}-\mathrm{S}_{2}-\mathrm{S}_{3}-\mathrm{S}_{4}$ are shown in Fig. 2(c).

Since the operation and detailed analysis of the twoinductor, two-switch buck converter in Fig. 1(a) was presented in [11] and [12], in this paper the analysis and operation of the two-inductor, four-switch buck converter in Fig. 2(a) is given.

\section{A. Principle of Operation}

To facilitate the explanation of the circuit operation, Fig. 3 shows a simplified circuit diagram of the circuit in Fig. 2(a). In the simplified circuit, it is assumed that filter capacitor $\mathrm{C}_{\mathrm{F}}$ and capacitors $\mathrm{C}_{1}$ and $\mathrm{C}_{2}$ are large enough so that the voltage ripple across them are small compared to their dc voltages. Synchronous rectifiers $\mathrm{S}_{\mathrm{R} 1}$ and $\mathrm{S}_{\mathrm{R} 2}$ are modeled as diode rectifiers $D_{1}$ and $D_{2}$, respectively. In this analysis it is also assumed that all semiconductor components are ideal, i.e., they represent zero impedances in the on state and infinite impedances in the off state. Finally, it is assumed that the conducting periods (i.e., $\mathrm{DT}_{\mathrm{S}}$ ) of switches $\mathrm{S}_{1}, \mathrm{~S}_{2}, \mathrm{~S}_{3}$, and $\mathrm{S}_{4}$ are equal.

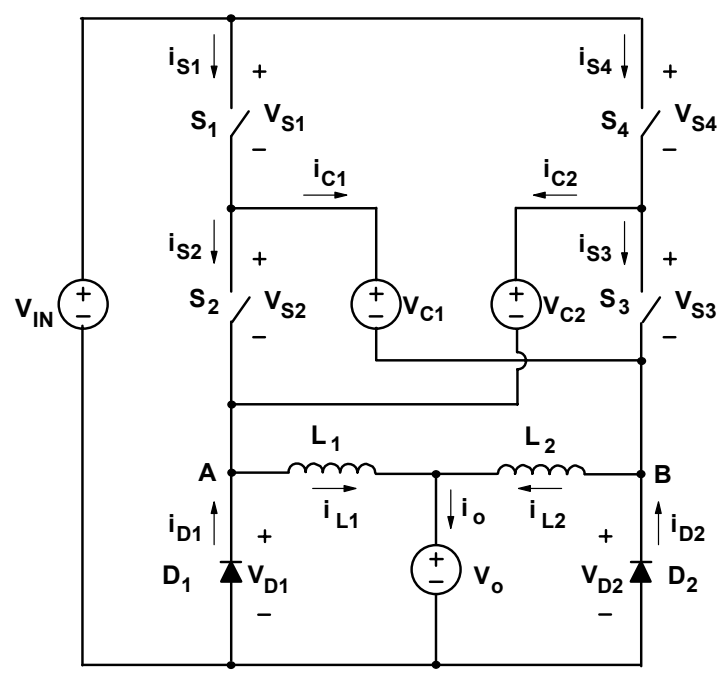

Fig. 3. Simplified circuit diagram of two-inductor, four-switch buck converter in Fig. 2 showing reference directions of currents and voltages. 


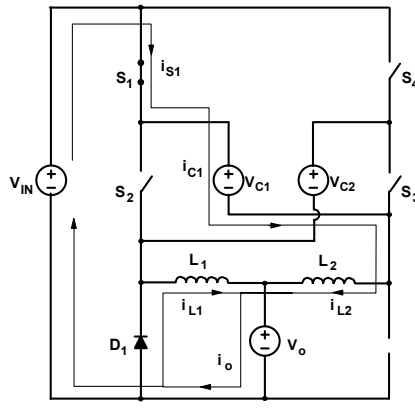

(a) $\left[T_{0}-T_{1}\right]$

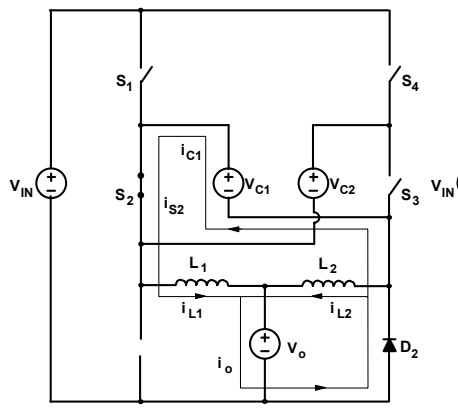

(c) $\left[T_{2}-T_{3}\right]$

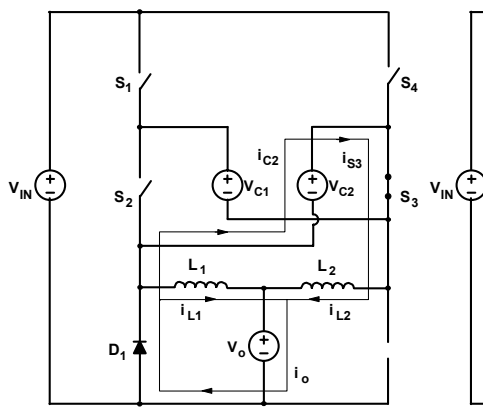

(e) $\left[T_{4}-T_{5}\right]$

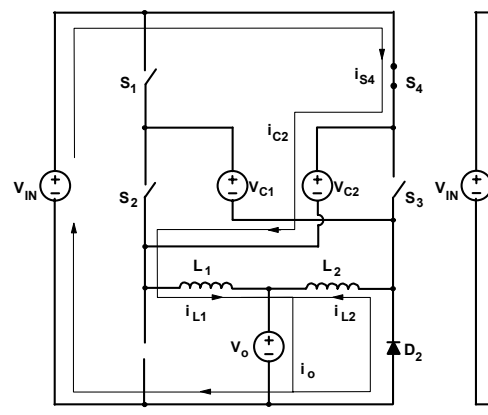

(g) $\left[T_{6}-T_{7}\right]$

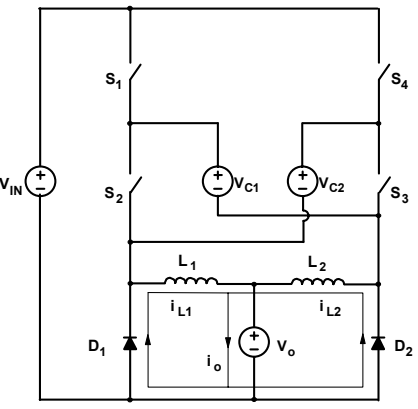

(b) $\left[T_{1}-T_{2}\right]$

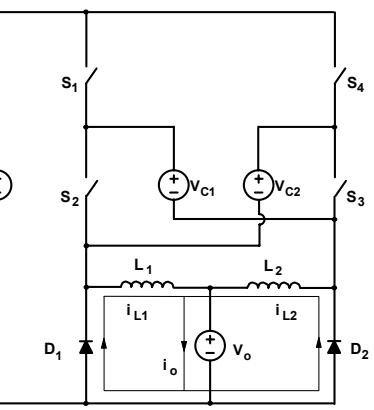

(d) $\left[T_{3}-T_{4}\right]$

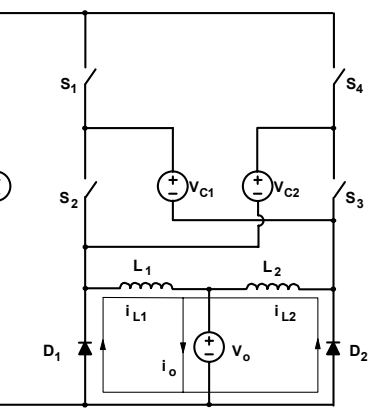

(f) $\left[T_{5}-T_{6}\right]$

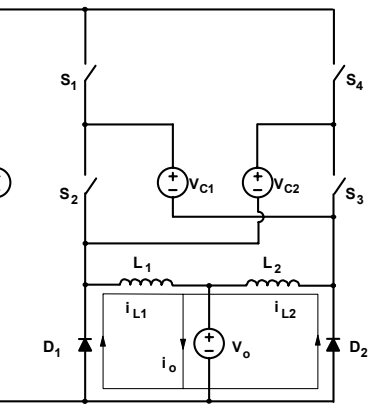

(h) $\left[T_{7}-T_{8}\right]$
Fig. 4. Topological stages of two-inductor, four-switch buck converter with four-phase interleaving control.

To further facilitate the analysis of operation, Fig. 4 shows the topological stages of the circuit in Fig. 3 during a switching cycle, whereas Fig. 5 shows its key waveforms for four-phase interleaved operation. The reference directions of currents and voltages plotted in Fig. 5 are shown in Fig. 3.

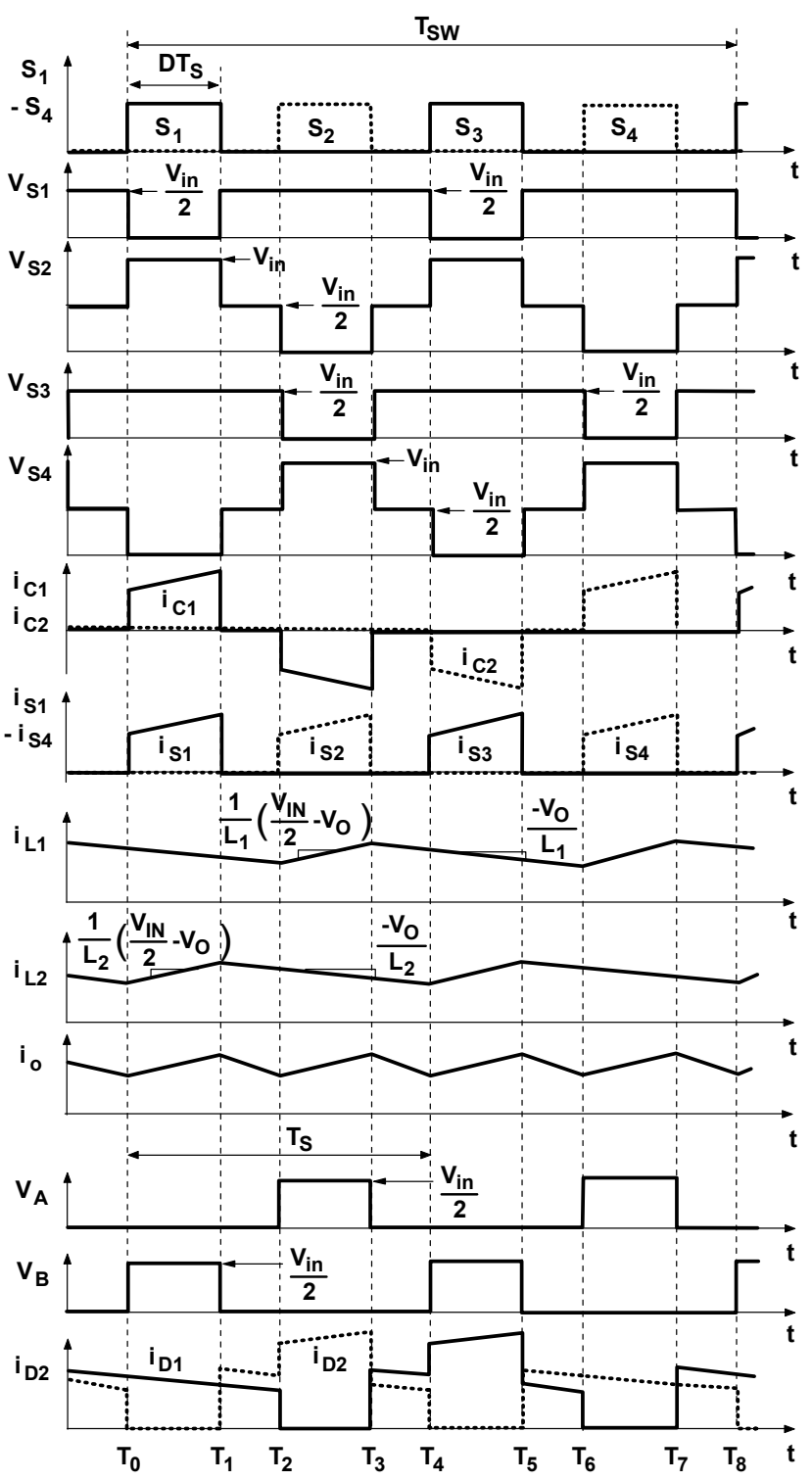

Fig. 5. Key waveforms of two-inductor, four-switch buck converter with four-phase interleaving control.

It should be noted that in steady state, the voltage across capacitor $C_{1}$ is equal to the average voltage across switch $S_{2}$ because the average voltages across inductors $L_{1}$ and $L_{2}$ are zero. From the waveform of voltage $\mathrm{V}_{\mathrm{S} 2}$ shown in Fig. 5, the average voltage across switch $\mathrm{S}_{2}$ can be easily derived as

$$
<\mathrm{V}_{\mathrm{S} 2}>=\mathrm{V}_{\mathrm{C} 1}=\mathrm{DV}_{\mathrm{IN}}+(1-2 \mathrm{D}) \mathrm{V}_{\mathrm{C} 1} \text {. }
$$

Solving Eq. (1) for $\mathrm{V}_{\mathrm{C} 1}$, it follows that

$$
\mathrm{V}_{\mathrm{Cl}}=\mathrm{V}_{\mathrm{IN}} / 2 \text {. }
$$

Similarly, it can be derived that voltage $\mathrm{V}_{\mathrm{C} 2}$ across capacitor $\mathrm{C}_{2}$, which is equal to the average voltage across switch $\mathrm{S}_{3}$, is

$$
\mathrm{V}_{\mathrm{C} 2}=\mathrm{V}_{\mathrm{IN}} / 2
$$


As shown in Fig. 4(a), during time interval $\left[\mathrm{T}_{0}-\mathrm{T}_{1}\right]$ when switch $\mathrm{S}_{1}$ is on, capacitor $\mathrm{C}_{1}$ is being charged by the input current flowing through switch $\mathrm{S}_{1}$, capacitor $\mathrm{C}_{1}$, and inductor $\mathrm{L}_{2}$ into output $\mathrm{V}_{\mathrm{O}}$. At the same time, the energy stored in inductor $\mathrm{L}_{2}$ is being increased because current $\mathrm{i}_{\mathrm{L} 2}$ increases at the rate

$$
\frac{\mathrm{di}_{\mathrm{L} 2}}{\mathrm{dt}}=\frac{\mathrm{V}_{\mathrm{IN}}-\mathrm{V}_{\mathrm{Cl}}-\mathrm{V}_{\mathrm{O}}}{\mathrm{L}_{2}}=\frac{\frac{\mathrm{V}_{\mathrm{IN}}}{2}-\mathrm{V}_{\mathrm{O}}}{\mathrm{L}_{2}} .
$$

During time interval $\left[\mathrm{T}_{0}-\mathrm{T}_{1}\right]$, the energy stored in inductor $\mathrm{L}_{1}$ is being discharged into the output by current $\mathrm{i}_{\mathrm{L} 1}$ flowing through diode $\mathrm{D}_{1}$ into output $\mathrm{V}_{\mathrm{O}}$. During this time interval inductor current $i_{L 1}$ decreases at the rate

$$
\frac{\mathrm{di}_{\mathrm{L} 1}}{\mathrm{dt}}=\frac{-\mathrm{V}_{\mathrm{O}}}{\mathrm{L}_{1}} \text {. }
$$

When at $\mathrm{t}=\mathrm{T}_{1}$, switch $\mathrm{S}_{1}$ is turned off, inductor current $\mathrm{i}_{\mathrm{L} 2}$ is diverted from switch $S_{1}$ to rectifier $D_{2}$, as shown in Fig. 4(b), and the energy stored in inductor $\mathrm{L}_{2}$ starts to discharge into output $\mathrm{V}_{\mathrm{O}}$. During time interval $\left[\mathrm{T}_{1}-\mathrm{T}_{2}\right]$, current $\mathrm{i}_{\mathrm{L} 2}$ decreases at the rate

$$
\frac{\mathrm{di}_{\mathrm{L} 2}}{\mathrm{dt}}=\frac{-\mathrm{V}_{\mathrm{O}}}{\mathrm{L}_{2}},
$$

while inductor current $\mathrm{i}_{\mathrm{L} 1}$ continues to decrease at the rate given in Eq. (5).

When at $\mathrm{t}=\mathrm{T}_{2}$, switch $\mathrm{S}_{2}$ is turned on, the circuit enters the topological stage shown in Fig. 4(c). During this topological stage, i.e., during time interval $\left[\mathrm{T}_{2}-\mathrm{T}_{3}\right]$, capacitor $\mathrm{C}_{1}$ is being discharged by inductor current $\mathrm{i}_{\mathrm{L} 1}$ flowing in the loop consisting of switch $\mathrm{S}_{2}$, inductor $\mathrm{L}_{1}$, output $\mathrm{V}_{\mathrm{O}}$, diode $\mathrm{D}_{2}$, and capacitor $\mathrm{C}_{1}$. In fact, during this topological stage, capacitor $\mathrm{C}_{1}$ serves as the input energy source to the buck converter with inductor $\mathrm{L}_{1}$. As the result of a positive voltage across inductor $L_{1}$, inductor current $i_{L 1}$ during time interval $\left[T_{2}-T_{3}\right]$ increases as

$$
\frac{\mathrm{di}_{\mathrm{L} 1}}{\mathrm{dt}}=\frac{\mathrm{V}_{\mathrm{Cl}}-\mathrm{V}_{\mathrm{O}}}{\mathrm{L}_{1}}=\frac{\frac{\mathrm{V}_{\mathrm{IN}}}{2}-\mathrm{V}_{\mathrm{O}}}{\mathrm{L}_{1}} .
$$

In the same time interval, current $\mathrm{i}_{\mathrm{L} 2}$ in inductor $\mathrm{L}_{2}$ continues to flow through diode $\mathrm{D}_{2}$ into the output, as shown in Fig. 4(c), and is decreasing at the rate given in Eq. (6).

When at $\mathrm{t}=\mathrm{T}_{3}$, switch $\mathrm{S}_{2}$ is turned off, the circuit enters the topological stage shown in Fig. 4(d), which is identical to the topological stage in Fig. 4(b). During this stage both switches are off and both inductors discharge their energy into the load. For equal values of inductances of inductors $L_{1}$ and $L_{2}$, currents $i_{L 1}$ and $i_{L 2}$ decrease at the same rates that are given by Eqs. (5) and (6).

After switch $\mathrm{S}_{3}$ is turned on at $\mathrm{t}=\mathrm{T}_{4}$, the circuit enters the topological stage shown in Fig. 4(e) that lasts until switch $\mathrm{S}_{3}$ is turned off at $\mathrm{t}=\mathrm{T}_{5}$. During this topological stage, capacitor $\mathrm{C}_{2}$ is being discharged by inductor current $\mathrm{i}_{\mathrm{L} 2}$ flowing in the loop consisting of switch $\mathrm{S}_{3}$, inductor $\mathrm{L}_{2}$, output $\mathrm{V}_{\mathrm{O}}$, diode $\mathrm{D}_{1}$, and capacitor $\mathrm{C}_{2}$, i.e., during this topological stage, capacitor $\mathrm{C}_{2}$ serves as the input energy source to the buck converter with inductor $\mathrm{L}_{2}$. Because of a positive voltage across inductor $\mathrm{L}_{2}$, inductor current $\mathrm{i}_{\mathrm{L} 2}$ during time interval $\left[\mathrm{T}_{4}-\mathrm{T}_{5}\right]$ increases at the rate

$$
\frac{\mathrm{di}_{\mathrm{L} 2}}{\mathrm{dt}}=\frac{\mathrm{V}_{\mathrm{C} 2}-\mathrm{V}_{\mathrm{O}}}{\mathrm{L}_{2}}=\frac{\frac{\mathrm{V}_{\mathrm{IN}}}{2}-\mathrm{V}_{\mathrm{O}}}{\mathrm{L}_{2}},
$$

During the same time interval, current $\mathrm{i}_{\mathrm{L} 1}$ in inductor $\mathrm{L}_{1}$ continues to flow through diode $\mathrm{D}_{1}$ into the output, as shown in Fig. 4(e), and decreases at the rate given in Eq. (6).

When at $\mathrm{t}=\mathrm{T}_{5}$, switch $\mathrm{S}_{3}$ is turned off, inductor current $\mathrm{i}_{\mathrm{L} 2}$ is diverted from switch $\mathrm{S}_{3}$ to rectifier $\mathrm{D}_{2}$, as shown in Fig. 4(f), and the energy stored in inductor $\mathrm{L}_{2}$ starts to discharge into voltage source $\mathrm{V}_{\mathrm{O}}$ at the rate given in Eq. (6) while inductor current $i_{\mathrm{L} 1}$ continues to decrease at the rate given in Eq. (5).

When at $\mathrm{t}=\mathrm{T}_{6}$, switch $\mathrm{S}_{4}$ is turned on, the input current starts flowing through switch $\mathrm{S}_{4}$, capacitor $\mathrm{C}_{2}$, and inductor $\mathrm{L}_{1}$ into output voltage source $\mathrm{V}_{\mathrm{O}}$, while the current in inductor $\mathrm{L}_{2}$ continues to flow through diode $\mathrm{D}_{2}$ into output $\mathrm{V}_{\mathrm{O}}$, as shown in Fig. 4(g). Namely, during the duration of this topological stage, capacitor $\mathrm{C}_{2}$ is being charged and at the same time the energy stored in inductor $L_{1}$ is being increased because current $i_{L 1}$ increases at the rate

$$
\frac{\mathrm{di}_{\mathrm{L} 1}}{\mathrm{dt}}=\frac{\mathrm{V}_{\mathrm{IN}}-\mathrm{V}_{\mathrm{C} 2}-\mathrm{V}_{\mathrm{O}}}{\mathrm{L}_{1}}=\frac{\frac{\mathrm{V}_{\mathrm{IN}}}{2}-\mathrm{V}_{\mathrm{O}}}{\mathrm{L}_{1}} .
$$

When at $\mathrm{t}=\mathrm{T}_{7}$, switch $\mathrm{S}_{4}$ is turned off, the circuit enters the topological stage shown in Fig. 4(h). During this stage both switches are off and both inductor currents $\mathrm{i}_{\mathrm{L} 1}$ and $\mathrm{i}_{\mathrm{L} 2}$ decrease with rates given by Eqs. (5) and (6), respectively.

The circuit enters a new switching cycle at $\mathrm{t}=\mathrm{T}_{8}$, when switch $\mathrm{S}_{1}$ is turned on again.

Voltage conversion ratio $\mathrm{M}=\mathrm{V}_{\mathrm{O}} / \mathrm{V}_{\mathrm{IN}}$ of the analyzed converter can be calculated from the volt-second balance of the output inductors. However, it should be noticed that in the converter in Fig. 2(a), the ripple frequency of output filter inductors $\mathrm{L}_{1}$ and $\mathrm{L}_{2}$ is twice the switching frequency of the individual switches $\mathrm{S}_{1}-\mathrm{S}_{4}$. With the notation used in Fig. 5, the volt-second balance equation for inductor $L_{2}$ is

$$
\left(\frac{\mathrm{V}_{\mathrm{IN}}}{2}-\mathrm{V}_{\mathrm{O}}\right) \mathrm{DT}_{\mathrm{S}}=\mathrm{V}_{\mathrm{O}}\left(\mathrm{T}_{\mathrm{S}}-\mathrm{DT}_{\mathrm{S}}\right)
$$

so that

$$
\mathrm{M}=\frac{\mathrm{V}_{\mathrm{O}}}{\mathrm{V}_{\mathrm{IN}}}=\frac{\mathrm{D}}{2} .
$$

As can be seen from Eq. (11), for the same duty cycle, the output voltage of the converter in Fig. 2(a) is one half of the output voltage of the conventional buck converter. This high step-down conversion ratio makes the converter suitable for applications with a high difference between the input and output voltage.

It should be noted that Eq. (11), which defines the voltagegain dependence on duty cycle of the converter in Fig. 2(a) with four-phase interleaving control sequence $\mathrm{S}_{1}-\mathrm{S}_{2}-\mathrm{S}_{3}-\mathrm{S}_{4}$, is only valid for duty cycles equal or less than $50 \%$, i.e., for $\mathrm{D} \leq 0.5$. Namely, if the duty cycle is greater than 0.5 , the conduction periods of switches $\mathrm{S}_{2}$ and $\mathrm{S}_{3}$ overlap causing a short across capacitors $\mathrm{C}_{1}$ and $\mathrm{C}_{2}$. 


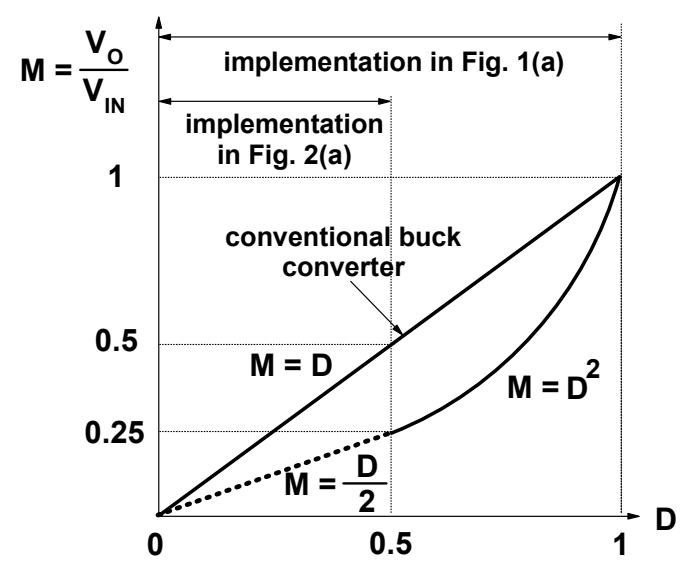

Fig. 6. Dependence of voltage-conversion ratio $\mathrm{M}$ on duty cycle of converters in Figs. 1(a) and 1(b) along with that of conventional buck converter.

Generally, the restricted duty-cycle range of the four-phase interleaved converter in Fig. 2(a) does not have any effect on the performance of the converter in VRM applications with a $12-\mathrm{V}$ input where the duty cycle never exceeds $50 \%$ even during no-load-to-full-load transitions. Furthermore, in applications that require operation with a duty cycle larger than $50 \%$, the implementation in Fig. 1(a) can be employed because this implementation offers a full-range duty cycle operation. For duty cycles $\mathrm{D} \leq 0.5$, voltage-conversion ratio $\mathrm{M}$ of the circuit in Fig. 1(a) is identical to that in Fig. 2(a), whereas for $\mathrm{D}>0.5$, voltage conversion ratio $\mathrm{M}$ of the circuit in Fig. 1(a) is

$$
\mathrm{M}=\frac{\mathrm{V}_{\mathrm{O}}}{\mathrm{V}_{\mathrm{IN}}}=\mathrm{D}^{2},
$$

as shown in Fig. 6 along with the corresponding dependence of the conventional buck converter.

\section{B. Design Considerations}

As can be seen from the voltage waveforms of all switches in Fig. 5, the drain voltage variation of each switch is only one half of input voltage $V_{\text {IN }}$ at the turn-on and turn-off instants, unlike the conventional buck converter, whose open switches block the full input voltage $\mathrm{V}_{\mathrm{IN}}$. Because the turn-on and turn-off switching losses due to the overlapping of the switch current and voltage waveforms are approximately proportional to the voltage across the switch and since the capacitive discharge turn-on loss is proportional to the square of the voltage across the switch prior to the turn-on, the switching losses of the proposed converter are very much reduced compared to those of the conventional buck converter. As a result, the proposed converter is expected to show better efficiency compared to its conventional multiphase counterpart at high frequencies where the switching loss is dominant.

In addition, because the maximum voltage stress on switches $\mathrm{S}_{1}, \mathrm{~S}_{3}, \mathrm{~S}_{\mathrm{R} 1}$, and $\mathrm{S}_{\mathrm{R} 2}$ is only $\mathrm{V}_{\mathrm{IN}} / 2$, as shown in Fig. 5, the converter can employ semiconductor switches with a lower voltage rating, which usually have lower on-resistances with respect to their higher voltage rated counterparts, resulting in a reduction of conduction loss. However, it should be noted that in the converter in Fig. 2(a), each switch carries one half of the load current, i.e., $\mathrm{I}_{\mathrm{O}} / 2$ compared to $\mathrm{I}_{\mathrm{O}} / 4$ that is carried by each switch in a four-phase conventional buck converter. Nevertheless, this difference in the switch currents does not significantly affect the performance of the converter. Namely, to have the same number of semiconductor switches as in the conventional four-phase buck converter, each synchronous rectifier $\mathrm{S}_{\mathrm{R} 1}$ and $\mathrm{S}_{\mathrm{R} 2}$ in the converter in Fig. 2(a) should be implemented with two switches in parallel so that each synchronous rectifier switch carries current $\mathrm{I}_{\mathrm{O}} / 4$. In addition, for high step-down ratios, e.g., $\mathrm{M}<0.2$, the conduction time of high-side switches $\mathrm{S}_{1}-\mathrm{S}_{4}$ is much shorter than that of synchronous rectifiers $S_{R 1}$ and $\mathrm{S}_{\mathrm{R} 2}$ so that the increase of conduction loss of switches $\mathrm{S}_{1}-\mathrm{S}_{4}$ due to their increased current is not very significant. To further minimize conduction losses, the capacitors $\mathrm{C}_{1}$ and $\mathrm{C}_{2}$ should be implemented by using low-ESR ceramic capacitors.

One very desirable feature of the proposed converter is the inherent and accurate current sharing between inductor currents $i_{\mathrm{L} 1}$ and $i_{\mathrm{L} 2}$ due to the fact that charging portions of the inductor currents flow through capacitors $C_{1}$ and $C_{2}$. Namely, if the charging portions of the currents become unbalanced, the voltage across capacitors $C_{1}$ and $C_{2}$ starts to deviate from the $\mathrm{V}_{\text {IN }} / 2$ value in the direction that balances the inductor currents. Because of this inherent current sharing, the interleaved controller for the converter in Fig. 2(a) does not need a current sharing loop, which makes the controller simpler compared to that of the conventional multi-phase buck converter.

\section{Concept Generalization}

The concept in Figs. 1(a) and 2(a) can be extended to any number of inductors and phases. In fact, the extension of the converter in Fig. 1(a) to the three-inductor, three-switch topology is given in [11] and [12]. The approach can be extended to n-inductor implementation as shown in Fig. 7.

Similarly, Fig. 8 shows the extension of the circuit in Fig. 2(a) to the three-inductor, six-switch step-down topology. This circuit can be operated either by three-phase or sixphase interleaved control. For a three-phase interleaved operation, the switching instances of pairs of switches that are switched simultaneously $\mathrm{S}_{1}-\mathrm{S}_{5}, \quad \mathrm{~S}_{2}-\mathrm{S}_{6}, \quad$ and $\quad \mathrm{S}_{3}-\mathrm{S}_{4}$ are interleaved, i.e., phase shifted by 120 degrees. For a six-phase operation, the switching instances of individual switches $S_{1}$, $\mathrm{S}_{4}, \mathrm{~S}_{2} \mathrm{~S}_{5}, \mathrm{~S}_{3}$, and $\mathrm{S}_{6}$ of the proposed converter are interleaved, i.e., phase shifted by 60 degrees.

The extension of the converter in Fig. 2(a) to the 2nswitch, n-inductor, step-down PWM converter is shown in Fig. 9. This circuit can be operated either with n-phase or $2 n$ phase interleaved control. The voltage gain of the converter 


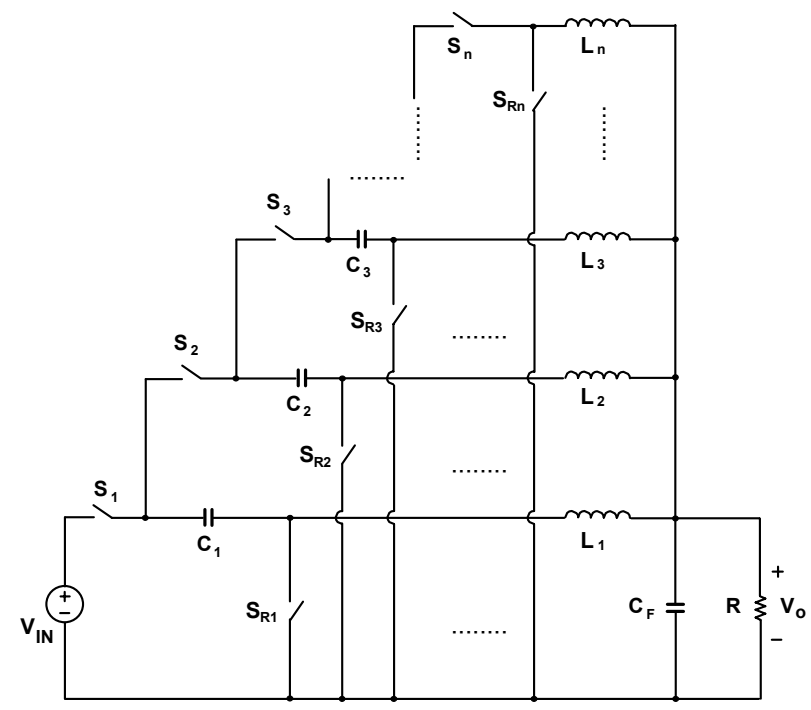

Fig. 7. Implementation of n-switch, $\mathrm{n}$-inductor, step-down PWM converter.

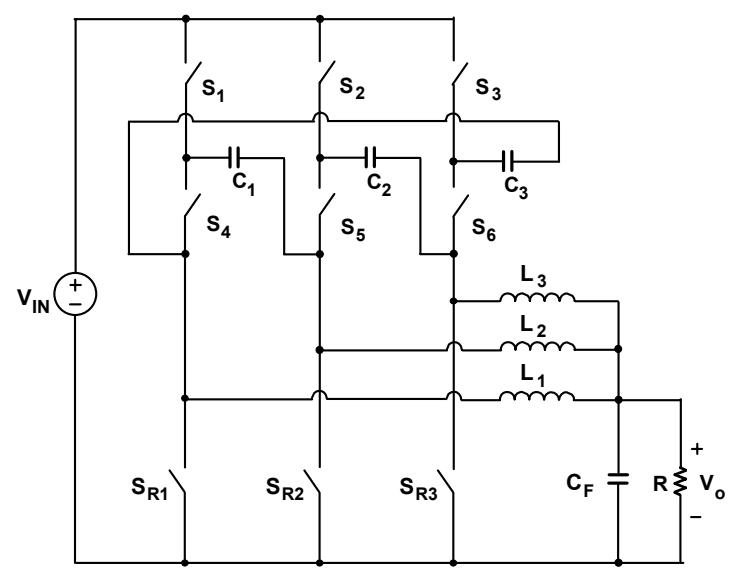

Fig. 8. Three-inductor, six-switch, step-down PWM converter.

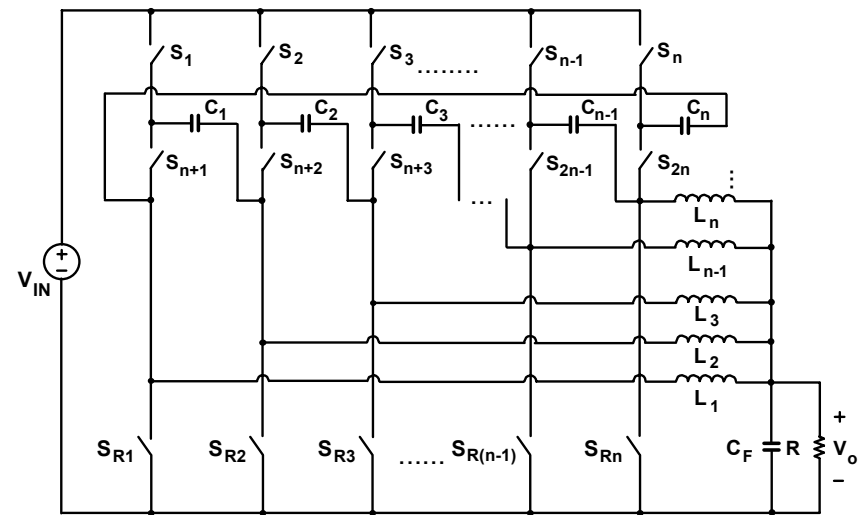

Fig. 9. Implementation of 2n-switch, n-inductor, step-down PWM converter.

shown in Fig. 9 is the same as that of the converter shown in Fig. 2(a).

Finally, it should be noted that the described concept of generating a family of multi-phase buck converters with high step-down gain can also be employed to derive a family of boost converters with increased step-up gain [11]. The gain of this family is identical to the gain of the boost converters introduced in [13].

\section{EXPERIMENTAL RESULTS}

The operation and the performance of the proposed converters with extended duty cycle was verified on a twophase, two-inductor converter in Fig. 1(a). The experimental $400-\mathrm{kHz}$ prototype was designed for a $12-\mathrm{V}$ input and a $1.25-$ $\mathrm{V}$ nominal output delivering a maximum current of $75 \mathrm{~A}$. Each high-side switch (i.e., $\mathrm{S}_{1}$ and $\mathrm{S}_{2}$ ) was implemented with a 20-V IRF6601 device, whereas each synchronous rectifier switch (i.e., $\mathrm{S}_{\mathrm{R} 1}$ and $\mathrm{S}_{\mathrm{R} 2}$ ) was implemented with two $20-\mathrm{V}$ IRF6609 devices in parallel. Five $10-\mu \mathrm{F} / 16-\mathrm{V}$ ceramic capacitors connected in parallel were used for blocking capacitor $\mathrm{C}_{1}$, each with $5-\mathrm{m} \Omega \mathrm{ESR}$, resulting in a $1-\mathrm{m} \Omega$ total ESR. Inductors $\mathrm{L}_{1}$ and $\mathrm{L}_{2}$ were implemented with an inductance of $0.43-\mu \mathrm{H}$ and winding resistance of $0.7-\mathrm{m} \Omega$. In

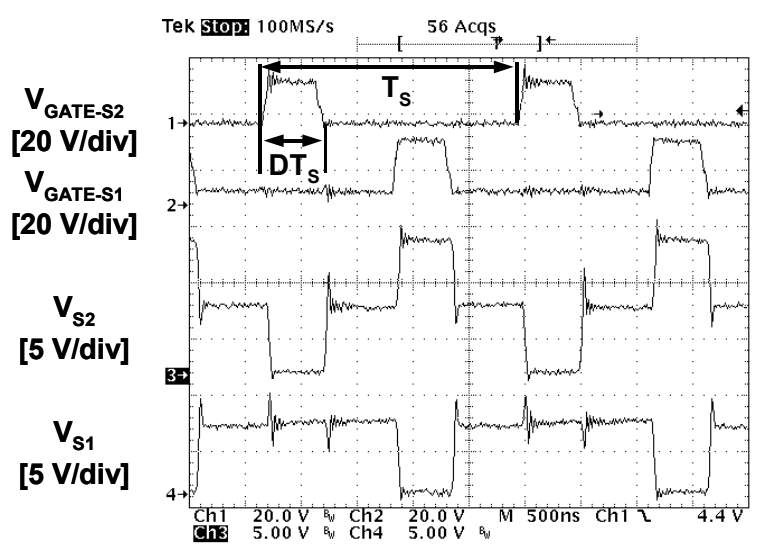

Fig. 10. Measured key waveforms of experimental prototype. From top to bottom: gate voltage $\mathrm{V}_{\mathrm{GATE}-\mathrm{S} 2}$ of $\mathrm{S}_{2}$; gate voltage $\mathrm{V}_{\mathrm{GATE}-\mathrm{S} 1}$ of $\mathrm{S}_{1}$; drain-source voltage $\mathrm{V}_{\mathrm{S} 2}$ of $\mathrm{S}_{2}$; drain-source voltage $\mathrm{V}_{\mathrm{S} 1}$ of $\mathrm{S}_{1}$. Time scale $500 \mathrm{~ns} / \mathrm{div}$.

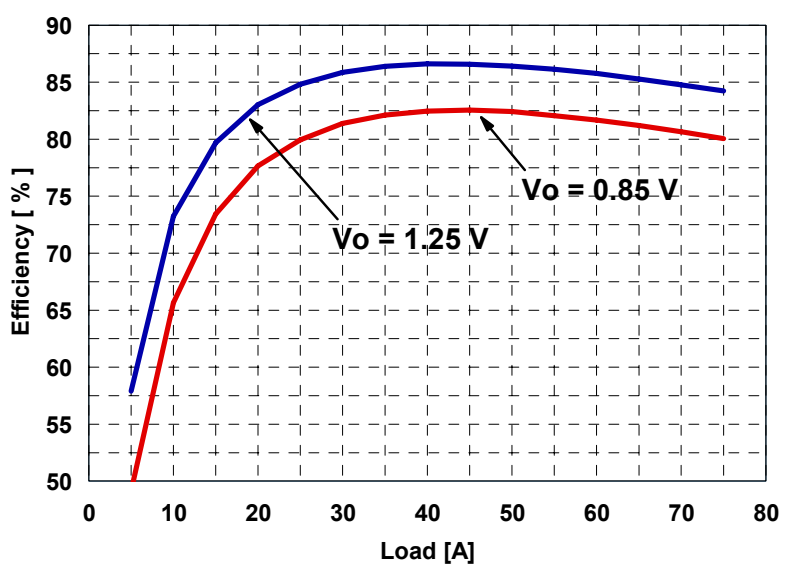

Fig. 11. Measured efficiencies of experimental prototype as functions of load current for $\mathrm{V}_{\mathrm{O}}=1.25 \mathrm{~V}$ and $\mathrm{V}_{\mathrm{O}}=0.85 \mathrm{~V}$. 
the absence of a dedicated multi-phase buck controller without a current-sharing loop, the general-purpose halfbridge voltage-mode controller ISL6740 from Intersil was employed. A pair of Intersil's ISL6613CB mosfet drivers was used to drive the switches.

The waveforms of gate voltages $\mathrm{V}_{\text {GATE-S1 }}$ and $\mathrm{V}_{\text {GATE-S2 }}$ of high-side switches $S_{1}$ and $S_{2}$ and their corresponding drainto-source voltages $\mathrm{V}_{\mathrm{S} 1}$ and $\mathrm{V}_{\mathrm{S} 2}$, measured at output voltage $\mathrm{V}_{\mathrm{O}}=1.25 \mathrm{~V}$ and load current $\mathrm{I}_{\mathrm{O}}=50 \mathrm{~A}$, are shown in Fig. 10. As can be seen from the figure, the experimental converter operates with a duty cycle of $22 \%$, which is twice as large as the duty cycle of the conventional buck converter with the same step-down ratio. Furthermore, by inspecting the drainto-source voltage waveforms $\mathrm{V}_{\mathrm{S} 1}$ and $\mathrm{V}_{\mathrm{S} 2}$, it can be seen that the experimental circuit exhibits lower voltage stress on switches $S_{1}$ and $S_{2}$ compared to its conventional counterpart. The peak voltage on switch $\mathrm{S}_{1}$, including the parasitic ringing, is around $8 \mathrm{~V}$, whereas the peak voltage on switch $\mathrm{S}_{2}$ is around $13 \mathrm{~V}$. Excluding the parasitic ringing voltage, the maximum voltage across switch $S_{1}$ is around $6 \mathrm{~V}$, whereas the maximum voltage across switch $S_{2}$ is $12 \mathrm{~V}$, i.e., the maximum voltages of switches $S_{1}$ and $S_{2}$ are $V_{\text {IN }} / 2$ and $V_{\text {IN }}$, respectively.

The measured efficiencies of the experimental converter for $\mathrm{V}_{\mathrm{O}}=1.25 \mathrm{~V}$ and $\mathrm{V}_{\mathrm{O}}=0.85 \mathrm{~V}$ as functions of the load current are shown in Fig. 11. The full-load efficiency of the experimental prototype is $84.2 \%$ at $\mathrm{V}_{\mathrm{O}}=1.25 \mathrm{~V}$ and $80.1 \%$ at $\mathrm{V}_{\mathrm{O}}=0.85 \mathrm{~V}$.

The measured full-load efficiencies are similar to those of the conventional two-phase buck converter built with the same components, which also has been confirmed in [12]. The full load efficiency of the proposed converter could be further improved by optimizing the high side switches. Generally, because high-side switches in the circuits of the proposed family exhibit larger conduction losses and reduced switching losses compared to those of their conventional counterparts, the optimized high-side switches should make a trade-off between the on-resistance and terminal capacitances in the direction of a reduced on-resistance. With optimized switches, the proposed converters have potential to show better performance than their conventional counterparts, especially as the switching frequency is pushed into the megahertz range.

\section{SUMMARY}

A family of multi-phase PWM step-down converters that feature a high voltage conversion ratio is introduced. The proposed multi-phase converters of the proposed family operate with larger duty cycles and lower voltage stresses on the switches than their conventional buck-converter counterparts. As a result, the proposed multi-phase converters are suitable for employment in high-frequency $\mathrm{dc} / \mathrm{dc}$ applications with very high step-down ratios such as, for example, in VR applications.

\section{REFERENCES}

[1] X. Zhou, X. Zhang, J. Liu, P. Wong, J. Chen, H. Wu, L. Amoroso, F. C. Lee, and D. Chen, "Investigation of Candidate VRM Topologies for Future Microprocessors", IEEE Applied Power Electronics Conference Proc., Feb. 15-19, 1998, pp. 145-150.

[2] Y. Panov and M. Jovanović, "Design Considerations for $12-\mathrm{V} / 1.5-\mathrm{V}$, 50-A Voltage Regulator Modules", IEEE Applied Power Electronics Conference Proc., Feb. 6-10, 2000, pp. 39-46.

[3] J. Wei and F. C. Lee, "A Novel Soft-Switched, High-Frequency, HighEfficiency, High-Current, 12-V Voltage Regulator - The Phase-Shift Buck Converter", IEEE Applied Power Electronics Conference Proc., Feb. 9-13, 2003, pp. 724-730.

[4] Y. Ren, M. Xu, K Yao, Y. Meng, and F. C. Lee, "Two-stage approach for 12 VR", IEEE Applied Power Electronics Conference Proc., Feb. 22-26, 2004, pp. 1306-1312.

[5] X. Zhou, B. Yang, L. Amoroso, F. C. Lee, and P-L. Wong, "A Novel High-Input-Voltage, High Efficiency and Fast Transient Response Voltage Regulator Module - Push-Pull Forward Converter", IEEE Applied Power Electronics Conference Proc., Mar. 14-18, 1999, pp. 279-283.

[6] J. Guo, "Double-Ended Transformer-Based Multiphase Converters", IEEE International Telecom. Energy Conference Proc., Oct. 19-23, 2003, pp. 104-109.

[7] Z. Yang, S. Ye, and Y. Liu, "A Novel Non-Isolated Half-Bridge Dc-Dc Converter", IEEE Applied Power Electronics Conference Proc., Mar. 6-10, 2005, pp. 301-307.

[8] J. Wei, P. Xu, H. Wu, F. C. Lee, K. Yao, and M. Ye, "Comparison of Three Topology Candidates for 12-V VRM", IEEE Applied Power Electronics Conference Proc., Mar. 4-8, 2001, pp. 245-251.

[9] P. Xu, J. Wei, K. Yao, Y. Meng, and F.C. Lee, "Investigation of Candidate Topologies for 12-V VRM", IEEE Applied Power Electronics Conference Proc., Mar. 10-14, 2002, pp. 686-692.

[10] K. Yao, F. C. Lee, Y. Meng, and J. Wei, "Tapped-Inductor Buck Converters With A Lossless Clamp Circuit for 12-V VRM", IEEE Applied Power Electronics Conference Proc., Mar. 10-14, 2002, pp. 693-698.

[11] Y. Jang and M. Jovanović, "Non-Isolated Power Conversion System Having Multiple Switching Power Converters", U.S. Patent Application 10/972,632, Oct. 26, 2004. Available at http://www.uspto.gov/patft/ after Apr. 27, 2006.

[12] K. Nishijima, K. Harada, T. Nakano, T. Nabeshima, and T. Sato, "Analysis of Double Step-Down Two-Phase Buck Converter for VRM", IEEE International Telecom. Energy Conference Proc., Sep. 18-22, 2005, pp. 497-502.

[13] L.C. Franco, L.L. Pfitscher, and R. Gules, "A New High Static Gain Non-Isolated Dc-Dc Converter," IEEE Power Electronics Specialists Conf. (PESC) Proc., Jun. 15-19, 2003, pp. 1367-1372. 